\title{
Effect of Astragalus Membranaceus on Patients with Metastatic Non-Small Cell Lung Cancer: A Retrospective Cohort Study
}

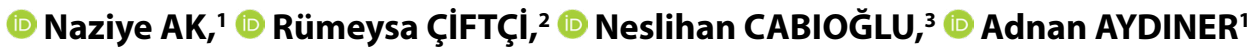 \\ 'Department of Medical Oncology, Istanbul University Institute of Oncology, Istanbul-Turkey \\ 2Department of Medical Oncology, Neolife Medical Center, Istanbul-Turkey \\ ${ }^{3}$ Department of General Surgery, Istanbul University Faculty of Medicine, Istanbul-Turkey
}

\begin{abstract}
OBJECTIVE
Astragalus membranaceus root extract (AMe) has been shown to have immunomodulatory effects on macrophages and Th1 type immune responses. Our goal was to determine whether AMe improves the overall survival (OS) of patients with metastatic non-small cell lung cancer (NSCLC).
\end{abstract}

\section{METHODS}

The medical charts of metastatic NSCLC were retrospectively reviewed. Histological subtype, performance status, age, gender, smoking status, comorbidities, chemotherapeutics, and erlotinib that were part of any type of treatment were recorded.

\section{RESULTS}

The median age of the patients was 61. The median follow-up period was longer for Group A (AMe users) than Group C (control group) (18 vs. 11 months, $\mathrm{p}<0.001$ ). At the time of analysis, $83.8 \%$ of the patients had died. Univariate analysis showed that OS was significantly longer in Group A than Group C (21 \pm 4.2 vs. $11 \pm 0.9$ months, $\mathrm{p}=0.004)$. In addition to AMe usage, female gender, smoking status, presence of hypertension, and erlotinib usage also had significant impacts on $\mathrm{OS}(\mathrm{p}<0.05$ for all variables). The multivariate analysis showed that only AMe (hazard ratio [HR]: 0.46, 95\% CI: $0.27-0.76, \mathrm{p}=0.003$ ) and erlotinib (HR: $0.45,95 \%$ CI: $0.22-0.89, \mathrm{p}=0.02$ ) usage were correlated with significantly longer OS.

\section{CONCLUSION}

Taking AMe during systemic anti-cancer treatment may significantly prolong OS of patients with metastatic NSCLC.

Keywords: Astragalus membranaceus; Herb; Mortality; Non-small cell lung cancer; Overall survival; Traditional Chinese medicine.

Copyright $\odot$ 2021, Turkish Society for Radiation Oncology

\section{Introduction}

Cancers of the lung and bronchus are the most common causes of cancer death. Patients with advanced non-small cell lung cancer (NSCLC) are treated with standard therapies such as chemotherapy (CT), im- munotherapy, radiation therapy, or with combination of them.[1,2] Astragalus membranaceus root extract (AMe) has a long history of medicinal use in Chinese herbal medicine as part of herbal mixtures to treat reduced vitality, which has symptoms such as fatigue, diarrhea, and lack of appetite. AMe, which has im- 
munomodulatory effects on macrophages and Th1 type immune responses, has been widely studied for its capability for immunopotentiation, apoptosis induction, and inhibition of inflammation and immunorestorative activity.[3-6] In vitro analysis has shown that AMe increases resistance to the immunosuppressive effects of CT drugs, stimulates macrophages to produce interleukin-6 (IL-6), and increases tumor necrosis factor.[7]

Astragalus saponin IV which is one of the active parts of AMe has been demonstrated that enhances chemosensitivity to cisplatin by inhibiting B7-H3. [5,8] B7-H3 is a member of the B7 family and broadly expressed on the transcriptional level in lymphoid and non-lymphoid organs. It complicates the immune response by regulating costimulatory and coinhibitory pathways. The anti-cancer effect of AMe extract is not only through its immunomodulatory effect but also through growth pathways, and perhaps some epigenetic effects. In a meta-analysis of 17 randomized studies with 1552 patients, Astragalus-based traditional Chinese medicine used with CT was associated with significantly increased overall survival (OS) and overall tumor response rates.[9]

This study aimed to determine whether AMe improves the survival results of patients with metastatic NSCLC, especially in patients with European descent.

\section{Materials and Methods}

The medical charts of patients who were admitted to Istanbul University, Institute of Oncology, Outpatient Medical Oncology Clinic between January 2017 and June 2017 to receive therapy for metastatic NSCLC were retrospectively assessed. The treatment principles of our institution are decided according to the current guidelines, after discussion with the multidiscipline team after each patient's visit. Of note, in our country, immunotherapies do not on the cover of governmental insurance, so immunotherapeutic agents cannot be used in our unit. Many patients have a tendency to use herbal replacements, and mostly immunologically based supportive treatments may make sense. When the patient conveys such a request in our clinic, we suggested the use of AMe, which has enough data about the use with targeted drugs and CT in previous publications. The suggested daily dose was 2-3 tablets of 250 mg AMe (Solgar, NJ, USA) minimum for 6 months.

We retrospectively collected the patients with minimum 6 months on Astragalus supplements during CT and targeted therapy. We record all medicine history along with supplement usage of patients at every visit routinely. The supplement had to be started with the first treatment cycle and used for at least 6 months. The patients who used minimum 6 months without other supplements and patients with no supplements as control group are included in the study. The exclusion criteria included being younger than 18 years old, using other group of herbal medicine, AM usage $<6$ months. Furthermore, patients with inadequate follow-up and had major record deficit in the file are excluded from the study. Each patient's informed consent was obtained before searching medical records for study either on phone call or at visit, informed consent was obtained from legal heir of patients who were death at the time of analysis. The study was approved by Istanbul University, Institute of Oncology, Institutional Review Board (Number: 70973125-604.01.01).

SPSS for Windows version of SPSS 20.0 (Chicago, IL., USA) was employed for data analysis and probability values $<0.05$ were considered statistically significant. The following variables were considered confounding factors in multivariate models: (1) Histological subtype, (2) high-risk comorbidities, (3) age, (4) gender, (5) smoking history, (6) performance status, and (7) cancer treatments (intravenous CT, oral CT, and targeted therapies) after diagnosis. The follow-up duration was calculated from the date of the diagnosis to the date of death or last follow-up visit. The OS was defined as the time of diagnosis to the date of death. Quantitative data were presented as the means with standard errors, medians with minimums and maximums. The results of qualitative analyses were presented as frequencies and percentages. Relationships and comparisons of several clinical variables were evaluated through Pearson Chisquare. Fisher's exact test was used where Pearson Chisquare test was inapplicable. We compared the OS of patients in Groups A and C using Kaplan-Meier estimates and the log-rank test for univariate analyses. Cox regression analysis was used to determine the association of AM usage and OS in the multivariate analysis.

\section{Results}

\section{Characteristics of Study Subjects}

A total of 117 metastatic NSCLC patients included this study who mostly were male gender (n: 109, 93.2\%). Four patients in the two groups were female and the majority of patients had non-squamous histology. Thirty-four patients (Group A) using AMe during systemic anti-cancer treatment were compared with 83 controls (Group C) that did not use AMe and another herbal supplement following NSCLC diagnosis. The median 
age of the patients was 61 (range: 42-81) and all patients were administered systemic treatment (CT or erlotinib). About $96 \%$ of patients received platin-based CT. There were no records that suggesting the side effect of the supplement, but these data did not indicate Grade 1 toxicities for laboratory results and toxicities that the patient did not complain since the assessments of patients were recorded before study. As for systemic treatments, patients had received, there were no differences in the proportion of patients with regard to comorbidities, type of intravenous CT, and oral targeted therapies. Only three patients from the control group and two patients from the AMe group did not receive platinum-based therapy. The histological subtype, performance status, age, gender, smoking status, comorbidities, usage of CT agents, and erlotinib were similar in Groups A and C (Table 1).

\section{Survival Results and Adjusted Hazard Ratio (HR) for Death between AMe Users and Control Group} The median follow-up period was significantly longer for A group than $\mathrm{C}$ group (18 vs. 11 months, $\mathrm{p}<0.001$ ). At the time of the analysis, $83.8 \%$ of the patients had died; 71 in Group C and 27 in Group A. In the univariate analysis, the median OS was significantly longer in Group A than Group C ( $21 \pm 4.2$ vs. $11 \pm 0.9$ months, $\mathrm{p}=0.004)$ (Fig. 1). In addition to AMe usage, female gender, smoking status, presence of hypertension, and erlotinib usage also had a significant impact on OS ( $\mathrm{p}<0.05$ for all) (Table 2$)$.

In the multivariate analysis, only AMe and erlotinib were associated with significant increases to OS. After adjusting for age, comorbidities, and conventional treatments, the Cox proportional hazard modeling revealed that the overall HR of death was 0.46 (95\% CI: 0.27-0.76, $\mathrm{p}=0.003$ ) in AMe users, compared with the control group (Table 3 ).

\section{Discussion}

With an increasing number of cancer patients seeking an improved quality of life, complementary and alternative therapies are becoming more common. According to the National Health Insurance database in Taiwan, the three most commonly prescribed herbs for cancer patients were Hedyotis diffusa, Scutellaria barbata, and AM.[10] Immune restorative effects of AMe on cancer patients were demonstrated in 1983 by Sun et al. first.[11] A number of studies deal with AMe's immunostimulatory and anti-cancer mechanisms. AME induces Ig production of murine B cells and improves white blood cell counts, the thymus index, the spleen index, CD4+/CD8+ ratio, TNF, IFN-, IL-2, and IL-17A

\begin{tabular}{|c|c|c|c|}
\hline & $\begin{array}{c}\text { Variables } \\
\text { group (\%) }\end{array}$ & $\begin{array}{l}\text { Control } \\
\text { AMe } \\
\text { group (\%) }\end{array}$ & $\mathbf{p}$ \\
\hline Age (years, median) & 61 & 60.5 & $0.48^{*}$ \\
\hline \multicolumn{4}{|l|}{ Age } \\
\hline$\leq 60$ & $39(47)$ & $17(50)$ & 0.76 \\
\hline$>60$ & $44(53)$ & $17(50)$ & \\
\hline \multicolumn{4}{|l|}{ Gender } \\
\hline Male & $79(95.2)$ & $30(88.2)$ & $0.22^{* *}$ \\
\hline Female & $4(4.8)$ & $4(11.8)$ & \\
\hline \multicolumn{4}{|l|}{ PS } \\
\hline ECOG 0-1 & $69(84.1)$ & $30(88.2)$ & $0.77^{* *}$ \\
\hline$E C O G \geq 2$ & $13(15.9)$ & $4(11.8)$ & \\
\hline \multicolumn{4}{|l|}{ Smoking } \\
\hline No & $10(12)$ & $8(23.5)$ & 0.11 \\
\hline Yes & $73(88)$ & $26(76.5)$ & \\
\hline \multicolumn{4}{|l|}{ Histologic subtype } \\
\hline Non-squamous & $57(68.7)$ & $21(61.8)$ & 0.47 \\
\hline Squamous & $26(31.3)$ & $13(38.2)$ & \\
\hline \multicolumn{4}{|l|}{ Hypertension } \\
\hline No & $51(61.4)$ & $15(44.1)$ & 0.08 \\
\hline Yes & 32 (38.6) & 19 (55.9) & \\
\hline \multicolumn{4}{|l|}{ IHD } \\
\hline No & $63(75.9)$ & $27(79.4)$ & 0.68 \\
\hline Yes & $20(24.1)$ & $7(20.6)$ & \\
\hline \multicolumn{4}{|l|}{ DM } \\
\hline No & $71(85.5)$ & $27(79.4)$ & 0.41 \\
\hline Yes & $12(14.5)$ & $7(20.6)$ & \\
\hline \multicolumn{4}{|l|}{ Gemcitabine } \\
\hline No & $27(32.5)$ & $8(23.5)$ & 0.33 \\
\hline Yes & $56(67.5)$ & $26(76.5)$ & \\
\hline \multicolumn{4}{|l|}{ Pemetrexed } \\
\hline No & $63(75.9)$ & $22(64.7)$ & 0.21 \\
\hline Yes & $20(24.1)$ & $12(35.3)$ & \\
\hline \multicolumn{4}{|l|}{ Taxane } \\
\hline No & $26(31.3)$ & $11(32.4)$ & 0.91 \\
\hline Yes & $57(68.7)$ & $23(67.6)$ & \\
\hline \multicolumn{4}{|l|}{ Etoposite } \\
\hline No & $77(92.8)$ & $30(88.2)$ & $0.47^{* *}$ \\
\hline Yes & $6(7.2)$ & $4(11.8)$ & \\
\hline \multicolumn{4}{|l|}{ Erlotinib } \\
\hline No & $64(77.1)$ & 25 (73.5) & 0.68 \\
\hline Yes & 19 (22.9) & $9(26.5)$ & \\
\hline \multicolumn{4}{|l|}{ Platinum } \\
\hline No & $3(3.6)$ & $2(5.9)$ & $0.62^{* *}$ \\
\hline Yes & $80(96.4)$ & $32(94.1)$ & \\
\hline \multicolumn{4}{|l|}{ Vinorelbine } \\
\hline No & 67 (80.7) & $30(88.2)$ & 0.32 \\
\hline Yes & $16(19.3)$ & $4(11.8)$ & \\
\hline $\begin{array}{l}\text { Follow-up period } \\
\text { (months) (median } \pm \\
\text { SE) (range) }\end{array}$ & $11 \pm 15.6(0-93)$ & $18 \pm 23(5-102)$ & $<0.001^{*}$ \\
\hline \multicolumn{4}{|l|}{ Last status } \\
\hline Exitus & 71 (85.5) & $27(79.4)$ & 0.41 \\
\hline Alive & $12(14.5)$ & $7(20.6)$ & \\
\hline
\end{tabular}

Chi-squared test; * Mann-Whitney U-test; **Fisher's exact test. AMe: Astragalus membranaceus extract; PS: Performance status; ECOG: Eastern cooperative oncology group; IHD: Ischemic heart disease; DM: Diabetes mellitus; SE: Standard error 


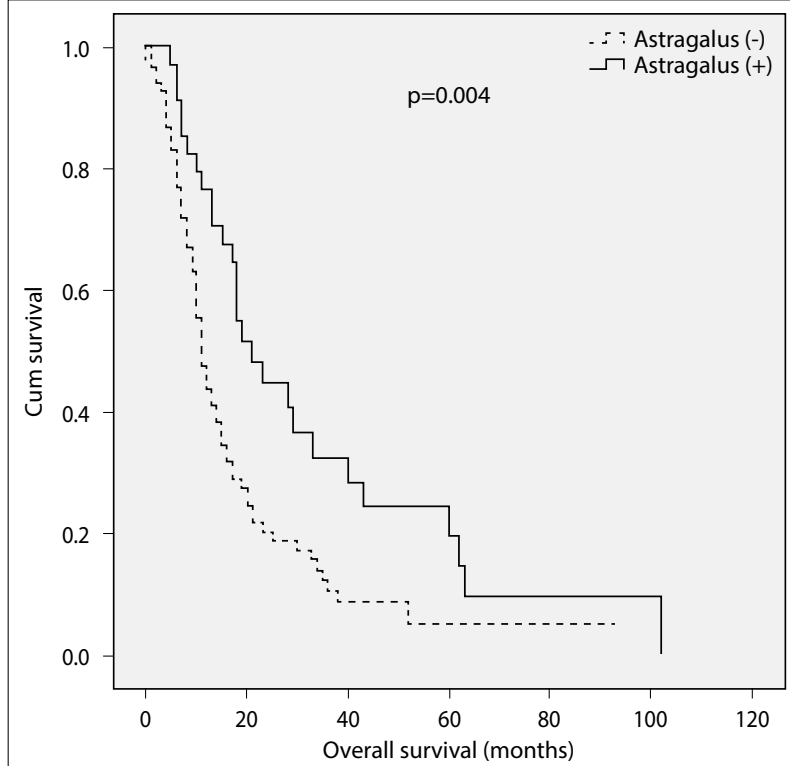

Fig. 1. The Kaplan-Meier plots of overall survival for patients who used Astragalus membranaceus root.

in mice with lung cancer.[12,13] Furthermore, AMe was found to be a potent immunomodulatory agent because it stimulated macrophages, so it could also be used as an immunotherapeutic vaccine adjuvant.[14]

The anti-cancer effect of AMe extract is not only through the immunomodulatory effect but also through growth pathways and perhaps through epigenetic effects. AMe inhibits cell proliferation and induces cell apoptosis through the PI3K/AKT/mTOR and ERK signaling pathways.[15-17] Furthermore, AMe modulated the invasiveness and angiogenesis of gastric adenocarcinoma cells through the way of metastatic proteins metalloproteinase (MMP)-2 and MMP-9.[4] This suggests that AMe may inhibit tumors' metastatic capabilities.

Our patient population is really in search of herbal treatments. Actually, this leads to the use of treatments of unknown origin that may cause serious side effects in patients. A long time we have met with very serious side effects that resulted from herbal medicine. Moreover, these searches sometimes led to the financial exploitation of our patients by malicious people. So based on literature, we recommended to AMe with commercial available form that has rational to offer to our patients who were seeking herbal supplement treatment advice to be clear to what they used. All studies that previously mentioned revealed questions about survival effect of supplement in our cohort, so we held this study. Although there are publications that suggest otherwise,[18] we have many more data that
Table 2 Univariate analysis of OS

\begin{tabular}{|c|c|c|c|}
\hline Variables & $\begin{array}{l}\text { No. of events/ } \\
\text { no. of total }\end{array}$ & Median $\pm S E$ & $\mathbf{p}^{*}$ \\
\hline \multicolumn{4}{|l|}{ Age } \\
\hline$\leq 60$ & $44 / 56$ & $15 \pm 2.2$ & 0.36 \\
\hline$>60$ & $54 / 61$ & $13 \pm 1.8$ & \\
\hline \multicolumn{4}{|l|}{ Gender } \\
\hline Male & $93 / 109$ & $13 \pm 1.3$ & 0.035 \\
\hline Female & $5 / 8$ & $33 \pm 13.7$ & \\
\hline \multicolumn{4}{|l|}{ PS } \\
\hline ECOG 0-1 & $85 / 99$ & $13 \pm 1.5$ & 0.62 \\
\hline$E C O G \geq 2$ & $13 / 18$ & $16 \pm 8.5$ & \\
\hline \multicolumn{4}{|l|}{ Smoking } \\
\hline No & $13 / 18$ & $34 \pm 19$ & 0.002 \\
\hline Yes & $85 / 99$ & $12 \pm 1.3$ & \\
\hline \multicolumn{4}{|l|}{ Histologic subtype } \\
\hline Non-squamous & $65 / 78$ & $15 \pm 1.6$ & 0.16 \\
\hline Squamous & $33 / 39$ & $10 \pm 1.7$ & \\
\hline \multicolumn{4}{|l|}{ Gemcitabine } \\
\hline No & $24 / 35$ & $14 \pm 1.8$ & 0.7 \\
\hline Yes & $74 / 82$ & $13 \pm 1.7$ & \\
\hline \multicolumn{4}{|l|}{ Pemetrexed } \\
\hline No & $73 / 85$ & $11 \pm 1.7$ & 0.07 \\
\hline Yes & $25 / 32$ & $18 \pm 3.8$ & \\
\hline \multicolumn{4}{|l|}{ Taxane } \\
\hline No & $31 / 37$ & $14 \pm 2.4$ & 0.77 \\
\hline Yes & $67 / 80$ & $13 \pm 2.1$ & \\
\hline \multicolumn{4}{|l|}{ Etoposite } \\
\hline No & $88 / 107$ & $13 \pm 1.4$ & 0.76 \\
\hline Yes & $10 / 10$ & $18 \pm 1.6$ & \\
\hline \multicolumn{4}{|l|}{ Erlotinib } \\
\hline No & $76 / 89$ & $11 \pm 1.1$ & $<0.001$ \\
\hline Yes & $22 / 28$ & $28 \pm 6$ & \\
\hline \multicolumn{4}{|l|}{ Platinum } \\
\hline No & $5 / 5$ & $15 \pm 8.7$ & 0.73 \\
\hline Yes & $93 / 112$ & $13 \pm 1.7$ & \\
\hline \multicolumn{4}{|l|}{ Vinorelbine } \\
\hline No & $79 / 97$ & $14 \pm 1.4$ & 0.31 \\
\hline Yes & $19 / 20$ & $11 \pm 3.4$ & \\
\hline \multicolumn{4}{|l|}{ Hypertension } \\
\hline No & $54 / 66$ & $12 \pm 1.6$ & 0.015 \\
\hline Yes & $44 / 51$ & $17 \pm 3.4$ & \\
\hline \multicolumn{4}{|l|}{ IHD } \\
\hline No & $73 / 90$ & $13 \pm 2.5$ & 0.84 \\
\hline Yes & $25 / 27$ & $14 \pm 1.9$ & \\
\hline \multicolumn{4}{|l|}{ DM } \\
\hline No & $82 / 98$ & $14 \pm 1.6$ & 0.49 \\
\hline Yes & $16 / 19$ & $12 \pm 1.3$ & \\
\hline \multicolumn{4}{|l|}{ AMe } \\
\hline No & $71 / 83$ & $11 \pm 0.95$ & 0.004 \\
\hline Yes & $27 / 34$ & $21 \pm 4.28$ & \\
\hline
\end{tabular}

Kaplan-Meier estimator, *Log-rank test. OS: Overall survival; PS: Performance status; ECOG: Eastern cooperative oncology group; IHD: Ischemic heart disease; DM: Diabetes mellitus; AMe: Astragalus membranaceus extract; SE: Standard error 
Table 3 Multivariate analysis of OS

\begin{tabular}{lccc} 
Variables & HR & $\mathbf{9 5 \%}$ Cl & p \\
\hline Age>60 versus $\leq 60$ years & 1.39 & $0.9-2.15$ & 0.12 \\
Gender: Female versus male & 0.54 & $0.2-1.46$ & 0.22 \\
Smoking: (+) versus (-) & 1.06 & $0.46-2.4$ & 0.89 \\
HT: (+) versus (-) & 0.76 & $0.47-1.26$ & 0.29 \\
IHD: (+) versus (-) & 0.9 & $0.52-1.56$ & 0.71 \\
DM: (+) versus (-) & 1.43 & $0.77-2.65$ & 0.25 \\
Gemcitabine: (+) versus (-) & 0.75 & $0.42-1.33$ & 0.32 \\
Pemetrexed: (+) versus (-) & 1.15 & $0.67-1.97$ & 0.61 \\
Taxane: (+) versus (-) & 0.95 & $0.56-1.62$ & 0.86 \\
Etoposite: (+) versus (-) & 0.88 & $0.41-1.88$ & 0.75 \\
Erlotinib: (+) versus (-) & 0.45 & $0.22-0.89$ & 0.02 \\
Platinum: (+) versus (-) & 1.03 & $0.34-3.17$ & 0.94 \\
Vinorelbine: (+) versus (-) & 1.61 & $0.9-2.9$ & 0.1 \\
AMe: (+) versus (-) & 0.46 & $0.27-0.76$ & 0.003 \\
ECOG-PS: 2-4 versus 0-1 & 0.91 & $0.47-1.75$ & 0.78 \\
Histology: Squamous & 1.27 & $0.75-2.14$ & 0.36 \\
versus non-squamous & & & \\
\hline
\end{tabular}

HR: Hazard ratio; Cl: Confidence interval; HT: Hypertension; IHD: Ischemic heart disease; DM: Diabetes mellitus; AMe: Astragalus Membranaceus extract; ECOG-PS: Eastern cooperative oncology group performance status scale

show longer OS with the combination of CT and AMe for lung cancer patients.[7,8] In a large meta-analysis of 34 randomized studies, Astragalus-based traditional Chinese medicine increased effectiveness of platinumbased CT. Twelve studies (940 patients) reported reduced risk of death within 12 months and 30 studies (2472 patients) reported improved tumor response. [7] Our data also showed that AMe increases OS despite different types of regimens, though this may be because near all of our patients used cisplatin doublets. As with CT, Astragalus and epidermal growth factor receptor (EGFR) tyrosine kinase inhibitor have an additive effect on EGFR mutant lung cancer, according to current literature. $[19,20]$ Consistent with these data, our results showed survival advantages of AMe in combination with erlotinib or CT. Although our population is relatively low, it may be a key population since other studies held in Asian countries.

Cancer patients frequently receive cardiovascular medications, including renin-angiotensin system blockers (RASBs), because cardiovascular diseases are common in the population. RASBs may provide synergistic effects with systemic cancer treatment by reducing angiotensin 2-mediated cell proliferation and angiogenesis.[21-23] Although, it lost significance in multivariate analysis, we also found that hypertensive patients using anti-hypertensive drugs showed significantly longer OS $(\mathrm{p}<0.05)$. In the multivariate analysis, $p$ value was very close to the significance level $(p=0.08)$, which may be due to the low number of cases.

There is little possibility for complete remission in metastatic lung cancer patients with CT alone. Immunotherapy may offer the best chance for a complete response.[2] The intersection of immune surveillance by tumor growth and development has led to significant therapeutic progress that is currently being studied in various cancer types, including lung cancer. Based on Phase III studies that show shown longer OS, Phase II studies have been approved for inhibitory antibodies PD-1 (pembrolizumab and nivolumab) and PD-L1 (atezolizumab, avelumab, and durvalumab). [7] Although immunotherapy is standard of care in lung cancer patients, immunotherapeutic agents are not covered by Turkish state insurance policy as many other middle- and low-income countries. This situation leads clinicians in our country to use complementary immunogenic therapies based on the scientific basis.

There are some limitations of this study that should be mentioned. Since this is a retrospective study, patient selection bias and time trend bias are inevitable. Another major limitation pertains to un availability of immunotherapies in our patient population that resulted better survival than conventional therapies we used. Although, we aimed to assess the effect of AMe, we cannot rule out imbalances or the heterogeneity of the treatment regimens utilized and toxicities of the systemic anti-cancer treatment that may have effect on survival results. Furthermore, again in this retrospective analysis, adverse events and toxicities that did not recorded could not be irrefutable.

\section{Conclusion}

Astragalus-based traditional Chinese medicine may have a potential clinical efficacy in the treatment of advanced NSCLC. More rationally designed trials are needed to investigate tumor response, survival, and quality of life of NSCLC patients using AMe. Astragalus extract may consider as a supportive care agent in metastatic NSCLC patients.

Acknowledgments: We did not receive substantial contribution from non-authors. This report was presented briefly as poster presentation at World Congress of Lung Cancer in 2017 at Yokohama, Japan. In addition, we used the STROBE cohort checklist when writing our report.[24]

Peer-review: Externally peer-reviewed.

Conflict of Interest: The authors have no conflicts of interest to declare. 
Ethics Committee Approval: Approved by Institutional Review Board in 2016.

Financial Support: This research did not receive any specific grant from funding agencies in the public, commercial, or not-for-profit sectors.

Authorship contributions: Concept - A.A., R.Ç.; Design - A.A., N.A.; Supervision - N.C., A.A., N.A.; Funding A.A.; Materials - A.A.; Data collection and/or processing - R.Ç., N.A.; Data analysis and/or interpretation - A.A., N.A.; Literature search - N.A.; Writing - N.A.; Critical review - N.A., R.Ç., N.C., A.A.

\section{References}

1. Planchard D, Popat S, Kerr K, Novello S, Smit EF, Faivre-Finn C, et al. Metastatic non-small cell lung cancer: ESMO clinical practice guidelines for diagnosis, treatment and follow-up. Ann Oncol 2018;29(Suppl 4):192-237.

2. Ettinger DS, Aisner DL, Wood DE, Akerley W, Bauman J, Chang JY, et al. NCCN guidelines insights: nonsmall cell lung cancer, version 5. 2018. J Natl Compr Canc Netw 2018;16(7):807-21.

3. Cho WC, Leung KN. In vitro and in vivo immunomodulating and immunorestorative effects of Astragalus membranaceus. J Ethnopharmacol 2007;113(1):132-41.

4. Auyeung KK, Woo PK, Law PC, Ko JK. Astragalus saponins modulate cell invasiveness and angiogenesis in human gastric adenocarcinoma cells. J Ethnopharmacol 2012;141(2):635-41.

5. Ren $S$, Zhang H, Mu Y, Sun M, Liu P. Pharmacological effects of Astragaloside IV: a literature review. J Tradit Chin Med 2013;33(3):413-6.

6. Block KI, Mead MN. Immune System Effects of Echinacea, Ginseng, and Astragalus: A Review. Integr Cancer Ther. 2003;2(3):247-67.

7. McCulloch M, See C, Shu XJ, Broffman M, Kramer A, Fan WY, et al. Astragalus-based Chinese herbs and platinum-based chemotherapy for advanced non-small-cell lung cancer: meta-analysis of randomized trials. J Clin Oncol 2006;24(3):419-30.

8. He CS, Liu YC, Xu ZP, Dai PC, Chen XW, Jin DH. Astragaloside IV enhances cisplatin chemosensitivity in non-small cell lung cancer cells through inhibition of B7-H3. Cell Physiol Biochem 2016;40(5):1221-9.

9. Wang SF, Wang Q, Jiao LJ, Huang YL, Garfield D, Zhang J, et al. Astragalus-containing traditional Chinese medicine, with and without prescription based on syndrome differentiation, combined with chemotherapy for advanced non-small-cell lung cancer: a systemic review and meta-analysis. Curr Oncol. 2016;23(3):188-95.
10. Cheng YY, Hsieh CH, Tsai TH. Concurrent administration of anticancer chemotherapy drug and herbal medicine on the perspective of pharmacokinetics. J Food Drug Anal 2018;26(2s):88-95.

11. Sun Y, Hersh EM, Lee SL, McLaughlin M, Loo TL, Mavligit GM. Preliminary observations on the effects of the Chinese medicinal herbs Astragalus membranaceus and Ligustrum lucidum on lymphocyte blastogenic responses. J Biol Response Mod 1983;2(3):227-37.

12. Shao BM, Xu W, Dai H, Tu P, Li Z, Gao XM. A study on the immune receptors for polysaccharides from the roots of Astragalus membranaceus, a Chinese medicinal herb. Biochem Biophys Res Commun 2004;320(4):1103-11.

13. Zhou X, Liu Z, Long T, Zhou L, Bao Y. Immunomodulatory effects of herbal formula of Astragalus polysaccharide (APS) and polysaccharopeptide (PSP) in mice with lung cancer. Int J Biol Macromol 2018;106:596-601.

14.Zhao LH, Ma ZX, Zhu J, Yu XH, Weng DP. Characterization of polysaccharide from Astragalus radix as the macrophage stimulator. Cell Immunol 2011;271(2):329-34.

15.Zhou R, Chen H, Chen J, Chen, X, Wen, Y, Xu L, et al. Extract from Astragalus membranaceus inhibit breast cancer cells proliferation via $\mathrm{PI} 3 \mathrm{~K} / \mathrm{AKT} / \mathrm{mTOR}$ signaling pathway. BMC Complement Altern Med 2018;18(1):83.

16. Auyeung KK, Mok NL, Wong CM, Cho CH, Ko JK. Astragalus saponins modulate mTOR and ERK signaling to promote apoptosis through the extrinsic pathway in HT-29 colon cancer cells. Int J Mol Med 2010;26(3):341-9.

17. Ohkawara S, Okuma Y, Uehara T, Yamagishi T, Nomura Y. Astrapterocarpan isolated from Astragalus membranaceus inhibits proliferation of vascular smooth muscle cells. Eur J Pharmacol 2005;525(13):41-7.

18. Cassileth BR, Rizvi N, Deng G, Yeung KS, Vickers A, Guillen S, et al. Safety and pharmacokinetic trial of docetaxel plus an Astragalus-based herbal formula for non-small cell lung cancer patients. Cancer Chemother Pharmacol 2009;65(1):67-71.

19. Liu ZL, Zhu WR, Zhou WC, Ying HF, Zheng L, Guo YB, et al. Traditional Chinese medicinal herbs combined with epidermal growth factor receptor tyrosine kinase inhibitor for advanced non-small cell lung cancer: a systematic review and meta-analysis. J Integr Med 2014;12(4):346-58.

20. Dai PC, Liu DL, Zhang L, Ye J, Wang Q, Zhang HW, et al. Astragaloside IV sensitizes non-small cell lung cancer cells to gefitinib potentially via regulation of SIRT6. Tumour Biol 2017;39(4):1010428317697555.

21. Ohnuma Y, Toda M, Fujita M, Hosono K, Suzuki T, 
Ogawa Y, et al. Blockade of an angiotensin type I receptor enhances effects of radiation on tumor growth and tumor-associated angiogenesis by reducing vascular endothelial growth factor expression. Biomed Pharmacother 2009;63(2):136-45.

22. Chauhan VP, Martin JD, Liu H, Liu H, Lacorre DA, Jain SR, et al. Angiotensin inhibition enhances drug delivery and potentiates chemotherapy by decompressing tumour blood vessels. Nat Commun 2013;4:2516.
23. Aydiner A, Ciftci R, Sen F. Renin-angiotensin system blockers may prolong survival of metastatic non-small cell lung cancer patients receiving erlotinib. Medicine (Baltimore) 2015;94(22):e887.

24.von Elm E, Altman DG, Egger M, Pocock SJ, Gotzsche PC, Vandenbroucke JP. The strengthening the reporting of observational studies in epidemiology (STROBE) statement: guidelines for reporting observational studies. J Clin Epidemiol 2008;61(4):344-9. 